\title{
Participação social e reforma psiquiátrica: um estudo de caso
}

\author{
Psychiatric reform and social participation: a case study
}

Alice Guimarães Bottaro deO Iiveira ${ }^{1}$

Marta Ester Conciani ${ }^{1}$

${ }^{1}$ Departamento de Enfermagem, Faculdade deEnfermagem, UFM T. Av. Fernando Correa da Costas/n, Campus

Universitário Coxipó da

Ponte. 78.060-900 Cuiabá

MT.alicegbo@yahoo.com.br
Abstract The psychiatric reform in Brazil articulates several dimensions - conceptual, technical, administrative, legislative and cultural. It is aimed at overcoming the psychiatric paradigm based on isolation and exclusion of the mentally ill. The Reform makes part of the Brazilian $\mathrm{H}$ ealth System and pre supposes a hierarchical system, municipality, participation and social control. Besides theadvances made in the administrative dimension, in the state of $M$ ato Grosso the reform takes place in centralized management contexts, revealing an apparent contradiction. Aim: Analyzing the participative processes in the construction of the psychiatric reform in Cuiabá and in the state of $M$ ato Grosso by means of analyses of documents of the $\mathrm{H}$ ealth Councils and Conferences held over the period 2000 to 2005. The fragility of the political processes of the $\mathrm{H}$ ealth Councils hampers their constitution as environments for articulating new practices. The process of changes toward the psychiatric reform is in accordance with a new management, determined by new financing models - re duction of hospitalizations and not hospital-centered care. This is possible because it is not a result of criticisms to the asylum logic represented in the analyzed dimensions of the Brazilian Health System. Key words M ental health, Consumer participation, Brazilian Health System, Mental health services, $\mathrm{H}$ ealthcare
Resumo A reforma psiquiátrica no Brasil articula várias dimensões - conceitual, técnica-assistencial, administrativa, legislativa e cultural - com o objetivo de superar o paradigma psiquiátrico que se estruturou em torno do isolamento e exclusão dos doentesmentais. Articula-seao SU S e pressupõehierarquização, municipalização, participação e controle social. Em M ato Grosso, apesar do avanço na dimensão administrativa, observa-se a sua realização em contextos de gestão centralizados, numa aparente contradição às suas raízes críticas. N osso objetivo éanalisar os processos participativos na construção da reforma psiquiátrica em Cuiabá e $M$ ato Grosso, por meio do estudo de documentos dos Conselhos e Conferências deSaúde produzi dos no período de 2000 a 2005. A fragilidadedos processos políticos dos Consel hos de Saúde dificulta a sua constituição como espaços articuladores de novas práticas. 0 processo de mudança rumo à reforma psiquiátrica se conforma como um novo desenho administrativo de gestão, determinado pelos novos modelos de financiamento - redução de internações e desospitalização - , sendo posśi vel sua realização em processos centralizados de gestão, pois não resulta de crítica à lógica manicomial representada nas instâncias do SUS analisadas.

Palavras-chave Saúdemental, Participação comunitária, SUS, Serviços de saúde mental, Atenção à saúde 


\section{O SUS ea reforma psiquiátrica}

As mudanças no campo da saúde no Brasil ocorreram em função de um movimento político reformador iniciado na década de 1970, motivado pela necessidade de abertura política do país - democratização em todos os setores, inclusive no da saúde. Esses ideais reformistas vêm se consolidando de forma mais expressiva desde 1986, quando, devido à necessidade de introduzir mudanças no setor com o objetivo detorná-lo democrático, acessível, universal eeqüitativo ${ }^{1}$, formalizou-senaVIII Conferência Nacional de Saúde (CNS), a participação de usuáriosna definição das diretrizes e princípios do Sistema Único de Saúde (SUS).

A Lei $n^{\circ} 8.080 / 90$ estabeleceos princípios do SUS e, dentre eles, o oitavo cita a participação da comunidade. Com o objetivo de dispor sobre essa participação na gestão do SUS, a Lei n $8.142 / 90$ defineas instâncias colegiadas do SUS - Conferência e Conselho de Saúde - sua composiçãoo e atribuições.

No processo de democratização do acesso à saúde e constituição do SUS, militantes políticos, técnicos e associações de familiares e portadores e detranstorno mental se mobilizavam para queessa reforma pudesse promover mudanças também no campo da saúde mental, através da inversão na lógica de tratamento dispensado a esse grupo. Esse movimento ficou conhecido como reforma psiquiátrica que, principalmente sob inspiração do movimento iniciado na Itália, desenvolveu-se no Brasil a partir da década de 1970.

A partir dos anos oitenta enoventa, vários segmentos têm se mobilizado e construído experiências de transformação no campo das práticas de assistência em saúde mental em todo o território nacional. Entretanto, não se pode afirmar que haja uma uniformidade cronológica ou geográfica nessemovimento nacional. Embora houvesseum acúmulo teórico critico, construído desde os anos setenta a respeito das práticas repressivas historicamente localizadas no hospital psiquiátrico, até 0 início dos anos noventa, as experiências deimplantação de serviços comunitários de saúde mental se constituíram como movimentos localizados em contextos específicos. Algumas decisões do M inistério da Saúde, a partir dos anos noventa, influíram mais incisivamentena política nacional de re forma psiquiátrica. Alguns dados do Ministério da Saúde são esclarecedores desse processo: no período de 1991 a 2006, o número de leitos em hospitais psiquiátricos no SUS decresceu de 85.037 para 42.036, e o número de Centros de Atenção Psicossocial (CAPS) aumentou de 4 para 8002.

A política de redução de leitos nos hospitais psiquiátricos e implantação de CAPS em todo o território nacional, desencadeada pelo M inistério da Saúde, constitui um importante instrumento administrativo no processo de reforma psiquiátrica; entretanto, é necessário destacar que essa se constitui e se mantém articulando várias dimensões - técnica-assistencial, conceitual, administrativa, política, legislativa ecultural - com o objetivo de superar o paradigma psiquiátrico que se estruturou em torno do isolamento e exclusão dos doentes mentais nos hospitais psiquiátricos ${ }^{3}$.

A reorientação paradigmática demandou a organização de uma rede de atenção psi cossocial que passa pela abertura de serviços especial izados e pela organização/reorganização de ações e serviços na rede local, mais especificamente, no fortal ecimento de ações assistenciais no nível primário de atenção, conforme orientação declarada em Caracas, em 1990, como marco dos processos de reforma da assistência em saúde mental nas Américas4.

Principalmente a partir de 2002, observam-se decisões emanadas do M inistério da Saúde no sentido de que a constituição de uma rede de atenção psicossocial substitutiva dos hospitais psiquiátricos fosse uniformizada para todo o território nacional. Destaca-se, nesse processo de organização administrativa da atenção psicossocial, no ano de 2002, a edição das Portarias n GM /336 eSAS/189, queregulamentam os CAPS e o seu financiamento e priorizam esse equipamento na rede de atenção em saúdemental; ea de $n^{\circ} \mathrm{GM} / 251$, queestabelece diretrizes e normas para a assistência hospitalar em psiquiatria, reclassifica os hospitais psiquiátricos e define a porta de entrada para as internações psiquiátricas na rede do SUS4.

Essas portarias visam a normatizar o funcionamento dos dispositivos extra-hospitalares de atenção em saúde mental (CAPS), nos aspectos administrativo-financei ros, evalorizá-los na reforma psiquiátrica em construção. Aliado a isto, ainda as Portarias n GM/251 e SAS/1001 apontam para uma desvalorização no valor das Autorizações de Internação H ospitalar (AIH) dos grandes hospitais psiquiátricos e valorização dos pequenos e médios, na medida em que estabelecem uma relação de quanto maior o número de leitos, menor 0 valor da AlH nos hospitais psiquiátricos. 0 objetivo foi redirecionar o modelo de atenção psiquiátrico, atéentão hospitalocêntrico, para a constituição de uma rede comunitária, territorial esubstitutiva dos hospitais psiquiátricos.

A Portarian ${ }^{\circ} \mathrm{GM} / 336$ inaugura um novo modelo de financiamento para estes serviços, inserindo os CAPS nas ações estratégicas do M inistério da Saúde. A remuneração desses serviços dar-se á através do sis- 
tema APAC/SIA (Autorização deProcedimento deAlta Complexidade/Custo), sendo incluídos na relação de procedimentos estratégicos do SUS e financiados com recursos do Fundo de ações Estratégicas e Compensação - FAEC. Dessa maneira, o principal órgão financiador dos CAPS passa a ser 0 gestor federal ${ }^{5}$.

Decorrentedesse processo administrativo emanado das diretrizes ministeriais, em $M$ ato Grosso tem acontecido um movimento de implantação de serviços componentes do novo modelo de atenção, como a criação de 27 CAPS no período de 1999 a 2005. Desses, quatro localizam-se em Cuiabá, onde também foram criados, em 2004, dez Serviços Residenciais Terapêuticos (SRT), em decorrência do fechamento do hospital privado conveniado neste mesmo ano. Portanto, ocorre, aparentemente, um avanço significativo na efetivação da política nacional de reforma psiquiátrica no sentido de criação de CAPS e desospitalização.

Observa-se também que, em decorrência da política de financiamento emanada do M inistério da Saúde, os gestores estaduais e municipais incorporaram a tendência de desospitalização na assi stência psiquiátrica moti vados pel a garantia do financiamento privilegiado para as ações extrahospitalares. N esse sentido, identifica-se em M ato Grosso um incentivo para a implantação de CAPS nos municípios com mais de 20.000 habitantes a partir de 2001, normatizado pelas Resoluções CIB $n^{\circ} 009 / 2001^{6} ; n^{\circ} 001 / 2002^{7}$ e Portaria $n^{\circ} 047 /$ SES/ $\mathrm{GS} / 2002^{8}$. A última, dispondo sobre o Programa de Incentivo a M icroregionalização na Saúde, especifica a forma e os valores desse incentivo8.

Esses instrumentos alteraram o panorama de assistência à saúde mental em M ato Grosso que, atéo início do século XXI, era caracteristicamente hospitalocêntrica?.

A partir dessa época, em decorrência dos instrumentos administrativos federais e estaduais acima apresentados, ocorreu um processo de "atração" dos gestores municipais para a criação de serviços extra-hospitalares na modalidade exclusiva de CAPS, decorrente do incentivo financeiro para implantação ecusteio. I sso possibilitou a criação de um número expressivo de CAPS em M ato Grosso e desencadeou algumas situações adversas, como os casos em que o gestor local, de posse dos recursos financeiros, atrasou a implantação e, assim, durante esse período, apesar de haver contratação da equipe, locação do imóvel e repasse mensal de recursos, não havia atendimento; e de muitos outros que, de forma recorrente, repassam apenas parcialmente, aos CAPS, o recurso mensal de custeio.

Considera-se que isso é possibilitado pelo fato dequehá, via de regra, uma ineficiência do controle da sociedade nas ações do Estado, que ocorrem por fal has no processo participativo ${ }^{10}$. Assim, apesar de haver um expressivo avanço na dimensão administrativa da organização da assistência à saúde mental em Cuiabá e M ato Grosso, indaga-se se essas mudanças no modelo de atenção não têm ocorrido em função da supremacia de uma lógica de gestão - redução de custos com internação, que repercute em desospitalização - mais do que em decorrência da participação social via Conselhos de Saúde, que deveriam se organizar em torno da formulação do Plano de Saúde adequado à formulação do SUS, a definição orçamentária do setor, a reorganização administrativa, o gerenciamento da rede, a alocação e remuneração dos profissi onais de saúdeeo próprio modelo assistencial ${ }^{1}$. Sendo profissionais envolvidos no processo local de reorganização da atenção à saúde mental, indagamos, como ponto de partida desse estudo, sobre a possibilidade de todos esses acontecimentos objetivamente relacionados ao processo de reforma psiquiátrica ocorrerem em períodos de gestão estadual e municipais marcados pela centralização e autoritarismo. As questões norteadoras foram: como é possível quea reforma psiquiátrica, que pressupõe participação social até mesmo nos processos tecno-assistenciais ou terapêuticos, pode se dar em contextos estranhos à participação social instituída no SUS? 0 movimento de reforma psiquiátrica local eregional relaciona-se à crítica social do hospital psiquiátrico e suas práticas excludentes de tratamento, está inserido no processo de construção do SUS, a partir de seus princípios de descentralização político-administrativa ede participação da comunidade, ou é um re-arranjo administrativo que visa a adequar a gestão às formas atuais de financiamento definidas pelo M inistério da Saúde?

Os objetivos foram analisar os processos participativos na construção da reforma psiquiátrica em Cuiabá; identificar os sujeitos sociais e segmentos participativos nos espaços de controle social; e, analisar as demandas de saúde mental debatidas nos Conselhos de Saúde Estadual de M ato Grosso e M unicipal de Cuiabá, suas origens eencaminhamentos.

Trata-se de uma pesquisa exploratório-descritiva, documental, deabordagem qual itativa. Compreendemos este estudo como referido ao campo denominado das Ciências Sociais. Como afirma $M$ inayo ${ }^{11}$, o objeto de estudo das ciências sociais é histórico, possui um caráter essencialmente qualitativo, além deser intrínseca e extrinsecamenteideológico, pois o sujeito pesquisador e objeto pesquisado estão "solidariamente imbricados". Assim, abordamos o objeto deste estudo tendo por refe- 
rência esses pressupostos teórico-metodológicos e buscando uma análise dialética da situação pesquisada. "A Dialética pensa a relação da quantidade como uma das qualidades dos fatos e fenômenos. Busca encontrar, na parte, a compreensão e a relação com o todo, e a interioridade e exterioridade como constitutivas dos fenômenos" ${ }^{\prime 1}$.

Ao identificarmos os dados desta pesquisa, buscamos compreen dêlos nesta realidade histórica especifica - o contexto do SUS e da reforma psiquiátrica - ao mesmo tempo em que buscamos circunscrevê-la na totalidade das relações sociais marcadas pelas contradições próprias do sistema socioeconômico brasileiro; tendo ainda a pretensão de apreendê-los na dinamicidade própria de um movimento social que se configura/reconfiguraconstantemente, pela multiplicidade deagentese processos envolvidos. A historicidade, dinamicidade e totalidade foram as balizas teórico-metodológicas desse estudo e estão referidas à dialética marxista. Entretanto, pela complexidade dos processos envolvidos nesta perspectiva analítica, temos essas premissas mais como um "ideal que perseguimos do que uma realidade que conquistamos"11.

Foram estudados atas e relatórios produzidos pelos Consel hos Municipal de Saúde de Cuiabá (CM S) e Estadual de Saúde de M ato Grosso (CES) no período de 01 de janeiro de 2001 a 30 de abril de 2005. As O uvidorias de Saúde do SU S, espaços extensivos dos Conselhos, também foram consideradasnesteuniverso. N esses documentos, foram identificadas as demandas relacionadas à saúde mental constantes de pautas e deliberações, segundo o segmento propositor e os encaminhamentos e deliberações a elas relacionados. Para isto, solicitou-se à secretaria executiva dos dois Conselhos acesso aos documentos acima listados. Ressalta-se que esses documentos, depois de aprovados em plenário, são de acesso irrestrito a todos os interessados.

Como pressuposto norteador do processo de análise dos dados, consideramos que à inclusão dos usuários e familiares nos processos terapêuticos, necessária para a consolidação do modelo psicossocial de assistência em substituição ao modelo manicomial ou hospitalocêntrico, corresponde a necessidade de participação e controle social nas esferas de decisão do SUS.

Com o objetivo de garantir o anonimato de todos os conselheiros que tiveram o registro de seus nomes nas atas, a transcrição de trechos de registros das atas será apresentada sem a menção nominal ao conselheiro, sendo substituído por um símbolo " $X$ ".

\section{Os espaços de partici pação e controlesocial}

No Brasil, a partir de 1980, a reorganização da sociedade rumo à recuperação dos espaços de representação política em diver sos setores eníveis se deu de acordo com os processos sociais locais, nas suas especificidades históricas. No setor saúde, o processo de inversão da lógica do modelo hospitalocêntrico, centralizado e verticalizado pelo nível federal, possibilitou que a municipalização fosse entendida, em princípio, como sinônimo de descentral ização e utilizada como panacéia para todos os males decorrentes da falência daquelemodelo, uma vez que está prevista nas leis do SU Sa descentralização político-administrativa-financeira ${ }^{12}$.

Todavia, esses dois princípios tão próximos possuem características intrínsecas que os diferem, a saber: a municipalização podeser entendida como o processo de responsabilização e autonomia dos municípios no que se refere à política de saúde em diferentes níveis e complexidades, num sistema de atenção ascendente e regionalizado, com recursos orçamentários específicos, autorizando e possibilitando sua organização. Essa, por sua vez, deve voltar-se para as necessidades locais, haja vista as enormes diferenças entre os municípios brasileiros. Enquanto a descentral ização é um meio que possi bilita a ampliação e a diversificação dos espaços de participação e de práticas sociais [...] traz consigo a potencialidade do alargamento da política, diversificando exatamente os campos de exercício da cidadania e favorecendo o reconhecimento da necessidade de se contemplar as diferenças na busca da equidade ${ }^{13}$.

A idealização de municipalização presente no início da reforma sanitária mostrou logo suas fragilidades. Entre os fatores que contribuíram para isto estão: a) a realidade do processo de municipalização muitas vezes reduzida à instância de barganha política de grupos locais, a "prefeiturização" do sistema de saúde, quando o município reproduz a lógica da hierarquia anterior ea conseqüente desconcentração em lugar da descentralização; b) a carência ou mesmo a ausência, nos municípios, de infra-estrutura e capacidade organizacional, de planejamento e de gestão do sistema de saúde; c) 0 receio de que a constituição de órgãos colegiados deliberativos resultasse em perda depoder político dos gestores e políticos locais; d) a necessidade e obrigatoriedadedo controlesocial se deparou com a realidade da organização social local, na quase totalidade dos casos, muito incipiente e, por isso, facilmente cooptada pelo executivo municipal ${ }^{12}$.

É principalmente sobre este último fator que nos deteremos, mas não o consideramos de maneira desarticulada de todos os outros. Todos com- 
põem uma totalidade dinâmica que dificultou 0 processo de descentralização previsto nas normas legais do SUS. Especificamente na questão dos recursos financeiros, muitas vezes os resultados deste processo foram desastrosos, marcados pelas conseqüências da criseeconômica epelo reordenamento da política rumo aos princípios neoliberais, que se efetivam desde então, e que determina que os recursos na área social sejam cada vez mais reduzidos, na constituição de um "Estado M ínimo"13.

Em Cuiabá, podem-se destacar alguns avanços: em meio ao processo de transição de modelo, organizou-se a saúde local com base no processo de regionalização (distritos sanitários), o CM S foi instalado em 1990 e, em 1993, foi realizada a primeiraConferência M unicipal deSaúde. Entretanto, em vez de seconstituir como espaço representativo dos anseios populares, um estudo sobre o funcionamento do CMS de Cuiabá nos seus primeiros cinco anos aponta um período marcado por embates entre o executivo, legislativo e as plenárias populares. Sua implantação ocorreu numa conjuntura autoritária e bastante desmobilizada no tocante à atuação dos movimentos populares. [...] permaneceu em sua primeira gestão voltado para atividades de caráter técnico e burocrático buscando a organização de sua estrutura, pouco fazendo em relação à Política de Saúde" e manteve, no período, "uma clara desarticulação do Conselho com os movimentos populares" eum atrelamento ao Executivo, deliberando, na maioria das vezes propostas levadas a Plenário pelo próprio Gestor do Sistema de Saúde, coincidindo apenas em al guns momentos com os interesses do conjunto dos consel heiros ${ }^{14}$.

Em meio ao processo de descentralização e municipalização do sistema de saúde e de organização das instâncias de participação social, as tensões eram evidentes e o risco de desvios ou equívocos do processo participativo, acentuado. A este respeito, observa-se que nesse quadro de funcionamento incipiente do CM S deCuiabá, ededefinição das forças políticas constituintes dessa arena, aconteceu, em 1995, uma importante discussão e proposição sobre saúde mental. Nesse ano, foi aprovada, no CM S de Cuiabá, uma política municipal de saúde mental com princípios e metas claramente identificados com a reforma psiquiátrica. Essa proposta, elaborada por um grupo de trabaIhadores de saúde mental, alunos e professores da primeira turma do Curso de Especialização em Saúde M ental da UFM T, articulado com representações dos trabal hadores com assento no CM S constava de "1) implantação de atendimento de saúde mental integrado à rede geral de serviços de saúde e nos três níveis de atenção; 2) implantação de lares abrigados para "pacientes moradores" de hospitais psiquiátricos; 3 ) instalação de núcleo interdisciplinar de educação continuada; e, 4) auditoria dos hospitais psiquiátricos" ${ }^{\prime \prime}$.

A discussão dessa temática ea aprovação desse plano no CMS, em agosto de 1995, foi resultante desse processo conflituoso e dinâmico de composição das forças políticas desse Conselho e da sua relação com o gestor municipal, os grupos informais e as representações de técnicos com assento no $\mathrm{CMS}^{16}$.

Esse avanço aparente do processo de participação social na definição da política municipal de saúde mental, quando analisado para além de sua aparência, indica um movimento contrário. 0 município, naquele momento da trajetória de municipalização das ações de saúde, quando assumiu a Gestão Semi-Plena do SUS, usufruía de maior autonomia administrativa e financeira, e dispunha de instâncias de participação e controle social formalmente constituídas (CMS), porém pouco representativas e fragilizadas sob o ponto de vista da participação cidadã. Em conseqüência, observou-se a tomada de decisões contrárias ao interesse da saúde da população, como o investimento maciço de recursos financeiros na compra de serviços de nível secundário e terciário e o desprestígio de medidas preventivas e de maior alcance na atenção primária16.

Nessa mesma época, quando o gestor municipal priorizava a atenção médica curativa em todas as áreas, o CMS aprovou uma política de saúde mental que apontava para a desinstitucionalização, com a organização de rede de assistência em todos os níveis, integrada à rede geral de serviços desaúde. 0 efeito mais visível resultantedesseconfronto foi uma redução do número de leitos contratados no hospital psiquiátrico privado com a correspondente redução dos recursos financeiros na área da assistência psiquiátrica. Das metas previstas no plano aprovado, foi implementada nos anos seguintes apenas a de criação de um ambulatório de saúde mental.

Considera-se que a aprovação de um novo modelo de atenção na área de saúde mental foi uma decisão de gestão que visava a uma global redução de custos nessa área e que se utilizou de um movimento de trabalhadores que, via CMS, tentava imprimir as diretrizes da reforma psiquiátrica na política local. Portanto, esse modelo de atenção aprovado, que aparentemente sinalizava para a construção da reforma psiquiátrica com seus desdobramentos técnico-políticos de crítica participativa ao modelo de atenção hospitalocêntrico, autoritário ediscriminatório anterior, na es- 
sência, se reduziu à diminuição dos recursos investidos pelo município na aten ção psiquiátrica.

A desinstitucionalização foi reduzida à desospitalização. Longe de se constituir como processo democrático e participativo, "ao contrário e paradoxalmente, ocorreu e foi possibilitada, por um processo de gestão centralizadora e que investia prioritariamentena atenção curativa eindividual" ${ }^{16}$.

É necessário considerar ainda, nesse incipiente processo de organização do SUS e de suas instâncias colegiadas, a instalação do CES de $M$ ato Grosso. Foi criado pelo decreto $n=1.055 / 88$, com alterações pelo decreto n-1.595 de 16/06/8917.

Não identificamos estudos sobre os primeiros tempos de funcionamento do CES; entretanto, Oliveira ${ }^{18}$ afirma que o hospital psiquiátrico privado local foi conveniado à rede pública a partir do dia 22/10/1990 com base em parecer do presidente do CES, ad referendum, eque, durante o pe ríodo detramitação do processo decredenciamento do hospital no CES, ocorreram manifestações contrárias à assinatura do convênio, por parte de conselheiros que consideravam que o credenciamento de leitos em hospitais psiquiátricos privados "significaria estimular um movimento que já estava sendo criticado em outras regiões brasileiras e já era questionado como prática terapêutica em âmbito nacional".

Destaca-se, portanto, na década de 1990, a fragilidade dos processos políticos do CM S Cuiabá e CES-M T em se constituírem como espaços articuladores de novas práticas em saúde mental, haja vista que o credenciamento do hospital psiquiátrico privado (1990) não se pautou pela análise realizada nestes consel hos, assim como a aprovação de uma política de saúde mental para o município de Cuiabá no CMS (1995) não repercutiu em ações de saúde mental na rede municipal.

Ao ressaltar também a fragilidade dos espaços participativos do SUS na arena de decisão política, principalmente na relação com o Executivo municipal, observa-se que a Lei Municipal № 2.820 de 19/12/1990, que regulamentava a organização e funcionamento do $\mathrm{CM} \mathrm{S}^{19}$, foi alterada no que se refere ao seu carater deliberativo quando, em 30/ 03/1998, foi aprovada a Lei Municipal no $3.731^{20}$ "contrariando a Lei Federal no 8142 de 28/12/1990 (Art. 1 ㅇ § 2을 e a Constituição do Estado de M ato Grosso (Art. 222) e, por essa razão, inconstitucional, esta Lei que impedia o CM S de qualquer ato decisório, vigiu até $2002 " 18$. Pode-se indagar, neste caso, sobre a qualidade da participação realizada nesse Consel ho, que se manteve formalmente pre senteno processo de gestão municipal nesse período - os Planos M unici pais de Saúdeeos Relatórios de Gestão foram aprovados e, dessa forma, garantiu-se o financiamento, também aprovado por este conselho.

É necessário ressaltar que esse processo não foi uniformeou harmônico; duranteesse período, existiram vozes discordantes, mas numa correlação de forças muito desigual. No entanto, a exemplo da marginalidade com que os movimentos populares participaram da crítica propulsora da reforma sanitária e psiquiátrica, essas vozes ainda que "fora" dos espaços "formais de participação" continuam nos dias atuais se constituindo como autênticos espaços de controle social, uma vez que na "marginalidade" seapresentam com a radicalidade daqueles que de alguma forma escapam às teias da institucionalização tão presente em alguns grupos sociais, que percebemos enredados pela sedução do discurso participativo do neoliberalismo.

Sobre a constituição dos espaços formais de participação como os do SUS, pode-se indagar se eles não estão referidos àqueles espaços autorizados pelo Estado para que aconteça a participação popular, ou seja, àqueles onde não se prioriza 0 despertar da cidadania, mas, ao contrário, onde as classes trabalhadoras são atraídas pel o Estado para atenuar a potencialidade de sua intervenção em questões mais centrais ${ }^{21}$.

A participação social tem caráter sempre contraditório, é espaço de del egação e autonomia, de decisão e cooptação, de participação e de alienação, como em toda arena de decisão política. A história brasileira decidadania tutelada, muito mais concedida pelo Estado do que conquistada pelas classes populares ${ }^{22}$, éfundamental para que sepossa compreender a ocupação dos espaços de participação e controle social instituídos pelo SUS.

No Brasil, em decorrência da forma peculiar de constituição dos direitos - base da cidadania temos um panorama onde o Executivo é muito fortalecido em relação aos outros poderes da República ${ }^{23}$. Podemos constatar no processo histórico de constituição dos Conselhos de Saúde, nesse estudo, a realidade desta afirmação.

A exemplo do avanço na política de saúde por meio da mobilização política nacional pela democratização de todos os setores da sociedade, a ascendência dessa prática cidadã tão cara à sociedade civil - a participação - no campo da saúde pode ser abordada sob várias perspectivas. Para atender aos objetivos propostos nesse estudo, aqui é entendida em dois sentidos dialeticamente articulados: a participação como integração do indivíduo no processo terapêutico (exercício de liberdade e de autonomia) é indissociável da participação como processo de construção democrática do SUS 
(exercício de cidadania). Admite-se que a inversão da lógica manicomial só pode ser constituída por meio da organização de uma rede articulada na qual se priorize a atenção psicossocial inserida em contextos solidários e comunitários. Com efeito, só podem existir serviços comunitários de saúde mental em sociedadeseinstituições democráticas ${ }^{24}$. Para tanto, é preciso que as unidades de saúde do SUS na sua relação com a população usuária seja horizontalizada, conforme prevêo modelo de saúde amparado nas Leis n 8.080/90 e 8.142/90.

A relação indissociável entre as experiências de sofrimento psíquico e a condição socioeconômica da população, seja no processo de adoecimento ${ }^{25}$, seja na organização interna e externa dos serviços deatenção de modo a que sejam resolutivos ${ }^{26}$, levanos a considerar que a participação comunitária, queinclui a participação instituída no SUS, seconstitua, por si, numa experiência socioterapêutica.

Desde o movimento italiano, que influenciou a crítica ao paradigma psiquiátrico que possibilitaria a idéia atualmente posta no Brasil de atenção psicossocial, sabe-se que não podemos perder de vista a extrema ambigüidade da situação que estamos vivendo, pois, só assim conseguiremos evitar a edificação deuma nova ideologia: a do hospital aberto, das comuni dades terapêuticas, propostas como solução para o problema do doente mental. N ossa realidade está mergulhada num terreno profundamente contraditório, e a conquista da liberdade do doente deve coincidir com a conquista da liberdade de toda a comunidade ${ }^{24}$. Enquanto estamos mergulhados, no movimento de reforma psiquiátrica, numa autocrítica teórico-técnica einstitucional que visa ao fortal ecimento demecanismos democráticos eparticipativos dos hospitaispsiquiátricos edemaiscentros de atenção, estamos, paradoxalmente "inseridos numa realidadesocial dealto nível repressivo e competitivo" 24 .

Quando se busca a superação do paradigma psiquiátrico pela atenção psicossocial, a participação dos usuários nos serviços de saúde mental, inclusive na gestão desses, resulta em benefícios para todos os envolvidos, gestores, profissionais e usuáriose, nessesentido, novamente encontramos a indissociabilidade do processo participativo social-terapêutico nesse campo ${ }^{27}$.

Portanto, a partir desses princípios, adotamos, como fio condutor para a análise dos dados, que a crítica do paradigma psiquiátrico e de sua instituição emblemática, o manicômio, não se sustenta quando desarticulada da crítica aos outros "manicômios" institucionais - conselhos e gestão, por exemplo.
A saúde mental nos conselhos e conferências de saúde

Esse estudo, propondo-se a uma análise de documentos de um determinado período e local, guarda algumas especificidades. Ressalta-se a precarie dade da estrutura física eadministrativa destinada à produção e arquivamento dos documentos produzidos pelos consel hose, como estes se localizam nas estruturas físicas das secretarias de saúde e são presididos pelos respectivos secretários de saúde, as duas instâncias se confundem. Identifica-se, portanto, uma primeira dificuldade para a participação cidadã no âmbito do SUS.

$N$ as atas das reuniões do CES-M T analisadas, observa-se que a saúde mental não constou como ponto de pauta de nenhuma delas. Foram registrados temas de saúde mental apenas em informes oficiais e extraordinários, demandas da ouvidoria e homologação de Resoluções da Comissão Intergestora Bipartite Estadual (CIB). Pode-se afirmar que a política de saúde mental não foi objeto de discussão no CES-MT no período estudado; porém, ressalta-se que essa ausência não éuma peculiaridade da saúde mental. A política estadual de saúde é objeto de discussão somente na aprovação dos planos, relatórios e nas discussões de aspectos específicos de organização e problemas cotidianos dos serviços.

No CM S, a mesma situação foi encontrada, sendo a saúde mental pauta apenas por necessidades técnicas associadas à aprovação de projetos para financiamento ministerial, como exigência cartorial da obrigatoriedade da homologação do CM S em processos de criação de unidades especializadas de atenção psicossocial (que nem sempre se concretizaram) e ainda para convite de inauguração de serviços. Em 2003, ocorreu uma única exceção. Foi identificada uma tentativa de ampliar a discussão política no campo da saúde mental na esfera municipal quando uma entidade representativa de trabalhadores da saúde apresentou uma carta apontando as dificuldades, as fal has e as distorções na condução da saúde mental municipal e solicitando uma reunião extraordinária, em vista dos problemas apontados, com a seguinte pauta: "Assistência à saúdemental no município deCuiabá - diagnóstico, necessidades e planejamento". A pós duas reuniões, a discussão não repercutiu em mudanças ese esvaiu no rol de pautas reivindicatórias e cartoriais.

A realização da III Conferência Nacional de Saúde M ental em 2001 desencadeou um calendário de discussões preparatórias no nível estadual e municipal. No período de agosto a novembro des- 
se ano, observam-se registros nas atas dos conseIhos a este respeito. Destaca-se, no CES, a realização da II Conferência Estadual de Saúde M ental, juntamente com a I Conferência Estadual deVigilância Sanitária e a I Plenária Estadual de Conse Ihos de Saúde, realizada nos dias 29 e 30/10/2001. Há registros de um fato já decidido de realização conjunta, sem registros de análises, críticas ou riscos envolvidos neste processo participativo tão minimalista, uma vez que realizado em dois dias, com três temas. Indaga-se se houve omissão dos conselhei ros desta discussão ou se houve falha de registro das atas.

Isso reporta à idéia de que, muitas vezes, a participação e o controle social se incumbem da formalização do processo mais do que da dinâmica política, da explicitação dos conflitos e da participação nos processos decisórios. $E$, uma vez que se restringe à formalização, importa mais a realização e não a qualidade da participação. Dessa forma, realizou-se como previsto os três "eventos" e, na ata da 111 a reunião, realizada em 07 de novembro, destaca-se o seguinte informe:

A respeito das Conferências a técnica $X$ fez uma avaliação positiva em virtude da grande participação dos municípios do Estado/M T, acima de 50\% e ainda, pel o fato da discussão ter sido bastanteaprofundada. Apresentou o consolidado da VISA, faltando ainda a elaboração do consolidado da Saúde M ental.

Quando se têm três "eventos" conjuntos, podese prever uma participação numericamente elevada; entretanto, a qualificação desta participação precisaria ser esclarecida. Não há registro de apresentação do "consolidado" da II Conferência Estadual de Saúde M ental mencionado nessa ou em outra reunião a partir desta data. Também não foi encontrado o relatório desta conferência ou ne nhum outro documento similar, na Secretaria Executiva do CES, quando da coleta dos dados dessa pesquisa. Pela dinâmica de proposta, realização e finalização desta conferência relatadas acima, observa-se que a sua realização está mais afeta ao cumprimento de uma agenda do Conselho Nacional de Saúde para a realização da III Conferência $N$ acional de Saúde M ental que aconteceria em dezembro de 2001, do que ao disposto no Artigo $1^{\circ}$ da Lei n 8.142/1990, deque“A Conferência deSaúde reunir-se-á [...] para avaliar a situação de saúde e propor as diretrizes para a formulação da política de saúde".

Nesse mesmo processo preparatório, aconteceu a I Conferência M unicipal deSaúdeM ental em 2001. Na reunião do dia 4/9/2001, ata número 13/ 2001/CM S, observa-se o registro detal hado deuma discussão a respeito do modelo da etapa prepara- tória municipal para a Conferência Nacional de Saúde M ental (fórum, plenária ou conferência). Nessa discussão, apontou-se o movimento que ocorria no nível estadual, quanto ao modelo de discussão e quanto à realização conjunta com outra temática (vigilância sanitária). Inicialmente, observa-se a apresentação de uma proposta do segmento da gestão municipal eestadual: "[...] prosseguindo a consel heira $X$ apresentou sobre a realização do Fórum de Saúde M ental explicando sobre a organização e realização do fórum, previsto para os dias 19 e 20 de outubro e com número de participantes de 115". [a conselheira X era representante do segmento governo]

Observa-se a preocupação de reduzir custos com a real ização da conferência em detrimento da representação uma vez que, ao explicar o número pré-definido de 115 participantes, $A$ conselheira $X$ respondeu que o número de participantes envolvia 0 público alvo, mas admite que foi observado apenas na questão do custo e não em paridade.

Esse modelo de fórum e a realização conjunta com a Vigilância Sanitária, sugerido pelo segmento do governo a partir de um modelo adotado pelo CES, foi rejeitado pela plenária do CMS. Embora tenha havido um direcionamento por parte da gestão, houve um significativo momento de participação que resultou na deliberação do momento preparatório para a III Conferência Nacional de Saúde Mental na forma de Conferência Municipal exclusiva de saúde mental.

Foi notada no âmbito municipal a delegação de plenos poderes à comissão organizadora para realizar a conferência que ocorreu como previsto e não foi encontrado registro de aprovação de seu relatório no plenário do CMS, a exemplo do ocorrido na conferência estadual.

Sobre as demandas oriundas das Ouvidorias, no CES observou-se o registro de algumas denúncias rel acionadasà fal ta eà padronização demedicamentos psicotrópicos na redeassistencial. Além disso, na 115 a reunião, realizada em 10/04/2002, há 0 seguinte registro, seguido de deliberação do CES pelo arquivamento: Denúncia protocolada referente a possível irregularidade no Hospital X [psiquiátrico] e conforme Portaria $\mathrm{N}^{\circ} \mathrm{X}$, foi constituída Comissão de Sindicância para investigar a procedência dos fatos. A Comissão de municipalização concluiu pelo arquivamento, tendo em vista que o nome e 0 endereço do denunciante eram fictícios, o que gerou dificuldade de apuração, e ainda com base no relatório de auditoria do COSEAS, que não apontou irregularidade.

$\mathrm{Na}$ Ouvidoria municipal do SUS, as reclamações foram sempre sobre medicamentos, à exce- 
ção de uma única denúncia apresentada por trabalhadores do hospital psiquiátrico estadual que, em razão de perdas profissionais, encaminharam denúncia movidos pelo interesse corporativo etendo como pano de fundo questões relacionadas à assistência naquele hospital, em 2001.

A partir dessas observações, constata-se que as ouvidorias, responsáveis por apresentar aos consel hos os problemas enfrentados pela população, no tocante ao acesso aos serviços de saúde e na avaliação da política de saúde, também se mantiveram distantes das discussões acerca da política de saúde mental. Isto fica evidente na medida em que em seus arquivos foram encontradas somente denúncias que se pautaram na necessidade de medicamentos, exceto as duas já mencionadas.

Analisando-se os encaminhamentos dados àquelas duas denúncias, observa-se que a primeira, no âmbito do CES, não evidencia o assunto e ainda utiliza-se de siglas e abreviaturas desconhecidas e é arquivada por não ter autoria identificada. Denota-seuma dificuldadeno exercício decontrole social por normas tão rigorosas, presentes na gestão burocrática das políticas públicas e contrárias aos princípios do controle social. Este, para se efetivar, requer mecanismos democráticos eacessíveis de participação. A denúncia da ouvidoria municipal sequer foi apreciada pelo CMS, tendo sido encaminhada diretamente ao secretário de saúde, que também o presidia.

N os relatórios da IV e V Conferências Estaduais de Saúde, a saúde mental é apenas apontada em algumas recomendações, não sendo objeto de nenhuma pauta ou item especifico. A IV Conferência Estadual de Saúde foi realizada em 2000 e suas deli berações foram avaliadas na realização da $\checkmark$ Conferência. Essa avaliação consta do relatório da última ${ }^{28}$ e, nele, são observadas al gumas questões relacionadas à participação e controle social: Eixo temático VI Gestão participativa e controle social - 6. Garantir dotação orçamentária ao Conselho deSaúdee destinar um percentual do Fundo de Saúde para atender as demandas de sua secretaria executiva. Avaliação: a dotação orçamentária do conselho ainda está vinculada à dotação orçamentária do gabinete da SES e também não tem percentual próprio. [...] 28. Garantir a avaliação semestral e divulgação das resoluções das Conferências de Saúde. Avaliação: ação não efetivada.

O bserva-se, segundo esta avaliação, que havia uma vinculação e depen dência financeira do CES ao executivo estadual equeas deliberações das conferências não eram avaliadas sistematicamente no CES. Entre as deliberações aprovadas na V Conferência, repetiu-se essas duas propostas na íntegra.
Resta-nos indagar sobre o tempo e as condições necessárias para que elas deixem de ser "intenções" aprovadas nas conferências e se constituam em fatos concretos que viabilizem o exercício da participação comunitária no âmbito do SUS.

Não foi possível a análise do relatório da II Conferência Estadual de Saúde M ental, haja vista que o mesmo não foi localizado no CES e a versão encontrada na área técnica da SES-M T não estava finalizada. Resta-nos indagar sobre qual o grau de importância atribuído às deliberações das conferências - momento de consulta à população sobre a formulação das políticas. Uma vez que o que se decide nas conferências não está disponível na instância de partici pação e controle social (CES) para que possa ser avaliado, nem integralmentena área técnica do executivo responsável pela implantação da política nelas deliberada, pode-se constatar a redução dos espaços constituídos legalmente para a participação e o controle social a meros espaços formais e burocráticos, atrelados ao executivo e sem a dinâmica própria de uma arena de decisão política.

No relatório da I Conferência Municipal de Saúde M ental de Cuiabá, disponível na secretaria executiva do CMS, observa-se que não foi dado prosseguimento para muitas de suas deliberações, principalmente no tocante à: ampliação da rede municipal de serviços substitutivos ao hospital psiquiátrico; implantação a política de saúdemental aprovada no CM S em 1995 (auditoria dos leitos psiquiátricos, SRTs, atendimento de saúdemental inserido nos níveis primário, secundário eterciário da rede municipal de atenção a saúde); implantação de serviços para atendimento às demandas específicas ( crianças eadolescentes, dependentes químicos); priorização das ações de saúde mental no planejamento municipal; efetivação da participação e controle social na saúdemental, principalmente por meio do CM S; descentralização da redeassistencial com implantação de serviços abertos com atendimento em horário integral.

Ao analisar as deliberações das conferências e atas dos CES e CMS, observa-se que a função de avaliar a situação de saúde e propor as diretrizes para a formulação da política de saúde e as estratégias para o controle da execução da política de saúde, previstas no texto da Lei n 8.142/90 estão ainda distantes no que se refereà saúde mental em Cuiabá e M ato Grosso. 0 que se ressalta é a existência, nesses documentos, deformulações genéricas e inespecíficas que não se traduzem na realidade cotidiana da organização dos serviços e na assistência nessa área. 


\section{A distância entre os registros e a realidade}

A partir dos dados desta pesquisa, não foi possível identificar a dinâmica dos processos ocorridos na organização e efetivação da política de saúde mental e da rede de serviços em Cuiabá e M ato Grosso. No entanto, por meio de observação assistemática e da nossa participação como trabalhadores da área, é possível a identificação de fatos significativos ocorridos nesse período. Visando a relacionar os dados obtidos nos documentos analisados nesse estudo, com os da realidade objetiva vivenciada nesse período, uma vez que as indagações desse estudo partiram da vivência dessa realidade, são apresentados no Quadro 1, em ordem cronológi$\mathrm{ca}$, alguns acontecimentos relacionados à organização dos serviços e da política de saúde mental em Cuiabá e M ato Grosso.
Além desses acontecimentos situados em Cuiabá, foram implantados, nesse período, 22 CAPS em municípios do interior do estado, totalizando, em 2005, 27 em M ato Grosso.

$N$ a rede de assi stência à saúde mental, destacase, em Cuiabá, a concentração de serviços sob a gestão estadual, numa contradição aos princípios de descentralização, hierarquização e municipalização. Em conseqüência, observa-se um distanciamento destes dos demais serviços da rede do SUS e uma dificuldade na operacionalização de princípios estruturantes destes serviços substitutivos, como a territorialização ea participação social. Isso contraria o pressuposto de que a esfera privilegiada para a efetivação da democracia é o município, ao mesmo tempo em queessedistanciamento provoca maior fragilidade no processo participativo, uma vez que é somente nessa effera - no município

Quadro 1. Fatos ocorridos na política de saúde mental nas esferas estadual e municipal.

\begin{tabular}{|c|c|c|}
\hline Ano & Fato & Esfera de gestão \\
\hline 2001 & $\begin{array}{l}\text { Extinção da função de coordenador de saúde mental } \\
\text { Aumento de aproximadamente } 30 \% \text { no número de leitos psiquiátricos } \\
\text { credenciados no hospital privado } \\
\text { Inauguração do primeiro CAPS na rede municipal de saúde de Cuiabá }\end{array}$ & $\begin{array}{l}\text { Municipal } \\
\text { Estadual } \\
\text { Municipal }\end{array}$ \\
\hline 2002 & Inauguração de um CAPSi administrativamente anexado ao hospital psiquiátrico & Estadual \\
\hline 2003 & $\begin{array}{l}\text { Inauguração de um Pronto-atendimento psiquiátrico física e } \\
\text { administrativamente anexado ao hospital psiquiátrico }\end{array}$ & Estadual \\
\hline 2004 & $\begin{array}{l}\text { Inauguração de } 10 \text { SRT } \\
\text { Descredenciamento do hospital psiquiátrico privado local da rede SUS } \\
\text { Inauguração de um serviço de internação para adolescentes dependentes } \\
\text { químicos (de difícil acesso e distando aproximadamente } 20 \mathrm{Km} \text { do centro urbano } \\
\text { de Cuiabá) } \\
\text { Inauguração de CAPS para adolescentes dependentes químicos } \\
\text { Inauguração de CAPS II } \\
\text { A provação do Decreto municipal } n^{\circ} 4232 \text { de } 17 / 11 / 2004 \text { que cria o Programa de } \\
\text { Saúde M ental - PSM no âmbito do Sistema Único de Saúde-SUS de Cuiabá } \\
\text { Capacitação em Saúde M ental de } 16 \text { Equipes do Programa de Saúde da Família }\end{array}$ & $\begin{array}{l}\text { Municipal } \\
\text { Municipal } \\
\text { Municipal } \\
\text { Municipal }\end{array}$ \\
\hline 2005 & $\begin{array}{l}\text { Aumento de aproximadamente 400\% no número de leitos do hospital } \\
\text { psiquiátrico público local } \\
\text { Aprovação da Lei nº } 8.302 \text { em 18/03/2005 que cria o Centro Integrado de } \\
\text { Assistência Psicossocial Dom Camilo Faresin no M unicípio de Guiratinga. } \\
\text { Fechamento e em seguida re-inauguração do serviço de internação para } \\
\text { adolescentes dependentes químicos inaugurado em } 2004\end{array}$ & $\begin{array}{l}\text { Estadual } \\
\text { Estadual } \\
\text { Municipal }\end{array}$ \\
\hline
\end{tabular}

Fonte: observação/participação das autoras e Diário O ficial do Estado de M ato Grosso. 
- que a indignação cidadã pode, além de expressar, obter respostas. Somente nessa esfera a cultura da subalternidade, a submissão aos ditames do senhor pode mudar. Somente nessa esfera a transparência das ações públicas locais pode ser exigi da, conhecida e alterada 29.

Percebe-se a importância desses acontecimentos, quer seja no sentido do avanço da política de reforma psiquiátrica, ou no sentido oposto, o retrocesso e fortalecimento de práticas manicomiais. Neste processo contraditório, constatam-se al guns movimentos rumo à desinstitucionalização ou desospitalização psiquiátrica (SRTs, CAPS), enquanto outros se constituíram frontalmente contrários a esse movimento (expansão do setor de internação psiquiátrica e a abertura de serviço de internação para dependentes químicos com características manicomiais).

Esses movimentos contraditórios são de fato estruturantes de todo processo de mudança social, que nunca se constitui linearmente, mas sempre atravessado por forças opostas num jogo político que, nesse caso, mantém a hegemonia das instâncias do poder executivo estadual e municipal em face da precariedade das organizações comunitárias de participação e controle social. D estaca-se 0 fato de que essas contradições estão presentes em todo o processo de participação social analisado, ou seja, a participação e o controle social não foram incorporados - porque sequer foram demandados - nos processos decisórios. Elas se constituíram de modo marginal ao poder instituído, fortementepresenteno executivo.

Destaca-se também o caráter aparentemente aleatório, de implantação e fechamento de serviços, que não apresenta correspondência com a construção da reforma psiquiátrica. A criação e a extinção deserviços não ocorreram a partir deuma demanda dos representantes da população em espaços coletivos de decisão. Foram sempre emanados de processos de gestão e passaram ao largo desses espaços coletivos.

Ainda que predomine esta concepção primária de controle social, que torna a participação alvo do Estado - portador da verdade técnica e do poder decisório e executivo - os grupos sociais não deixaram de reagir por meio de uma "contra participação" com caráter de resistência, como ocorrido por exemplo, na revolta da vacina no Rio de Janeiro ${ }^{30}$. Como exemplos de "contra participação" ou resistência ao autoritarismo, observou-se em Cuiabá alguns movimentos:

a) Nos anos noventa, quando trabal hadores da saúdemental sejuntaram a iniciativa de professores do Núcleo de Estudos em Saúde M ental (NESM -
MT) da Faculdade de Enfermagem (FAEN)-UFM T e realizaram o I e II Encontro de Saúde M ental de $M$ ato Grosso, cujo objetivo era o de oportunizar uma discussão que culminasse em ações concretas para a implantação de um política de saúde mental em M ato Grosso, que resultou na constituição de um grupo que apresentou ao CM S um estudo sobre a assistência psiquiátrica em Cuiabá e, após algumas discussões, em 1995, este consel ho aprovou uma proposta de política de saúde mental, orientada pelos princípios da reforma psiquiátrica ${ }^{15}$;

b) Em 2005, diante da ameaça de abertura de um hospital psiquiátrico, novamente um movimento de contra participação foi percebido sob a condução de uma entidade representativa de trabalhadores da saúde (Consel ho Regional de Serviço Social). Por meio da discussão ampliada com outros segmentos, o gestor foi chamado a dar esclarecimentos através de audiência pública eainda que tenha afirmado dar continuidade ao projeto já transformado em lei, não se tem registros de sua concretização;

c) Também em 2005 houve a instalação do Fórum Permanente de Saúde M ental de M ato Grosso, originado no III Curso de Especialização em Saúde M ental do NESM -M T/FAEN-UFM T e que reúne profissionais e demais interessados em torno dos princípios do movimento de luta antimanicomial.

0 enfrentamento dessas situações de poder político diferenciado e exercício de cidadania remete-nos à questão dos direitos no campo da saúde mental. $\mathrm{Na}$ lida cotidiana com nossa vida, doentes ou não, somos seres humanos diferentes e, portanto, é necessário reconhecer essa diferença sem inscrevêla como desqualificação. Temos direito à diferença e devemos nos garantir, ao mesmo tempo, igualdade de direitos na medida em que desejamos e ousamos que assim o seja. Somos iguais porque desejamos sêlo [...] aqui, como em toda justa política, o direito não é um ben eficio recebido por vitimas, mas uma conquista efetuada por cidadãos, não é uma esmola medida pelo que não temos, maso presente sem preço que nos damos. [...] U ma sociedade sem manicômios não é uma meta situada no futuro, a uma distância segura de nós, não é um equilíbrio a ser alcançado, nem será jamais uma contradição a ser resolvida. U ma sociedade tal é o convívio que ousamos produzir, a luta que sabemos enfrentar - já e não um dia ${ }^{31}$.

A participação nos espaços de decisão, quenos constitui como cidadãos e, nesse sentido, como seres humanos "iguais" socialmente, é uma conquista a ser realizada cotidianamente na arena política dos serviços de saúde e dos espaços de parti- 
cipação e controle social do SU S. É garantia de cuidado integrado e integrador do campo psíquico, nos processos terapêuticos realizados nos dispositivos de atenção psi cossocial e está intrinsecamente ligada aos processos coletivos de participação e controle social no sistema de saúde.

\section{Consideraçõesfinais}

Conclui-se que o processo de mudança rumo à re forma psiquiátrica se conforma em M ato Grosso e Cuiabá como um novo desenho administrativo, de gestão, determinado pelos novos modelos de financiamento - redução de custos com internações e conseqüente desospitalização. Portanto, não há contradição na sua realização em processos de gestão centralizados, pois não resultam de crítica à lógica manicomial socialmente organizada e representada nas instâncias do SUS analisadas.

Embora legitimamente existam na área da saúde espaços privilegiados de controle social (conse-
Ihos de saúde e conferências), os espaços estudados não têm se ocupado da política de saúde mental. Enquanto as instâncias formais de participação do SUS encontram-se esvaziadas do estabelecimento de diretrizes e do controle da execução da política de saúde mental, outros espaços, informais e "marginais" aos instituídos, se constroem no contexto local.

Ora, se existe uma crítica de que as fragilidades na participação social no Brasil ocorrem em função da cultura de não participar herdada do processo de colonização e ditadura, no campo da saúdemental, em Basaglia ${ }^{24}$ encontramos o alerta para que não nos deixemos seduzir pelo caminho da homogeneização das diferenças, pela supremacia de uma tecnologia que se pretende solução para as contradições irreconciliáveis de nosso sistema social excludente e segregador. Assim, pois, ao pretendermos construir a reforma psiquiátrica, não é possível nos excluir dos processos participativos concedidos, conquistados ou autorizados - na sociedade eespecificamenteno SUS.

\section{Colaboradores}

AGB Oliveira e ME Conciani participaram igualmente de todas as etapas da concepção e elaboração do presente estudo e artigo, sendo ambas autoras principais do mesmo. 


\section{Referências}

1. Gerschman S. A democracia inconclusa: um estudo da reforma sanitária brasileira. Rio de Janeiro: Fiocruz; 1997.

2. Brasil. Ministério da Saúde. Saúde mental em dados. 2006 [acessado 2006 mar 29]. Disponível em: http:// portal.saude.gov.br/portal/sas/mental/area.cfm? id_area $=851$

3. Amarante P. A (clínica) e a reforma psiquiátrica. In: Amarante $P$, organizador. Archivos de saúde mental e atenção psicossocial. Rio de Janeiro: N au Editora; 2003. p. $45-66$.

4. Brasil. M inistério da Saúde. Legislação em saúde mental 1990 - 2004. 2006 [acessado 2006 mar 29]. Disponível em: http://portal.saude.gov.br/portal/arquivos/ pdf/Legislacao.pdf

5. Freire FHMA, Ugá MAD, Amarante P. Os centros de atenção psicossocial e o impacto do sistema de financiamento no modelo assistencial. In: Amarante P, organizador. Archivos de saúde mental e atenção psicossocial 2. Rio de Janeiro: Nau Editora; 2005. p. 113-142.

6. Resolução CIB n 009/2001 de 25 de maio de 2001. Dispõe sobre a flexibilização do processo de implantação e implementação dos Centros de Atenção Psicossocial (CAPS) em Mato Grosso. Diário Oficial do Estado de Mato Grosso 2001; 18 jun.

7. Resolução $\mathrm{CIB} n^{\circ} 001 / 2002$ de 22 de março de 2002. Dispõe sobre a alteração de materiais permanentes para implantação e implementação dos Centros de Atenção Psicossocial (CAPS) em Mato Grosso. Diário O ficial do Estado de M ato Grosso 2002; 12 jun.

8. Portaria $n^{\circ}$ 047/SES/GS/2002 de 15 de abril de 2002. Dispõe sobre a M icrorregionalização da saúde. Diário Oficial do Estado de M ato Grosso 2002; 13 mai.

9. Oliveira AGB, Alessi NP. Superando o manicômio? Desafios na construção da reforma psiquiátrica. Cuiabá: EdUFM T; 2005.

10. Conciani ME. Conselho Gestor de Saúde: um estudo de caso da experiência do Sucuri [monografia de curso de especialização]. Cuiabá (MT): Departamento de Serviço Social, Universidade Federal de M ato Grosso; 1998.

11. M inayo MCS. Ciência, técnica e arte: 0 desafio da pesquisa social. In: Minayo MCS, organizadora. Pesquisa social: teoria, método e criatividade. Petrópolis: Vozes; 1994. p.14-25.

12. Bordin R. Definição de prioridades em saúde: os conseIhos municipais de saúde e os critérios para hierarquização de prioridades. Porto Alegre: Dacasa; 2002.

13. Cohn A. Estado, políticas públicas e saúde. In: Canesqui AM, organizadora. Ciências Sociais e Saúde. São Paulo: Hucitec/Abrasco; 1997. p.157-172.

14. Silva IM F. Conselhos de saúde: construindo uma nova linguagem. Cuiabá: EdUFMT; 1998.

15. Rado MJS, Oliveira AGB, Santos JP, Vieira MAM, Andrade SM R, Gomes L. Proposta de Política de Saúde M ental para o M unicípio de Cuiabá. Cuiabá: Conselho Municipal de Saúde; 1995. [Mimeo]
16. Oliveira $A G B$, Silva $M A, M$ arcon $S R$. Atenção à saúde mental no nível primário: análise de uma experiência de integração ensino-serviço. Coletânea de Enfermagem 2000; 2(2):39-55.

17. M ato Grosso. Conselho Estadual de Saúde. 2006 [acessado 2006 jan 28]. Disponível em: http://www.saude. $\mathrm{mt}$. gov.br/site/arq_conselhoestadual.php

18. Oliveira AGB. A reforma psiquiátrica em Cuiabá/MT: análise do processo de trabalho das equipes de saúde mental [tese]. Ribeirão Preto (SP): Escola de Enfermagem de Ribeirão Preto, Universidade de São PauIo; 2003.

19. Lei Municipal no 2.820 de 19 de dezembro de 1990. Regulamenta os Artigos 164 a 170 da Lei Orgânica do M unicípio de Cuiabá referente à organização e funcionamento do Conselho Municipal de Saúde e dá outras providências. Diário Oficial de Cuiabá 1990; 22 dez.

20. Lei Municipal $n 03.731$ de 30 de março de 1998. Altera dispositivo da Lei № 2.820 de 19 de Dezembro de 1990 e dá outras providências. Diário Oficial de Cuiabá 1998; 02 abr.

21. Saes D. República do capital: capitalismo e processo político no Brasil. São Paulo: Boitempo; 2001.

22. Demo P. Cidadania tutelada e cidadania assistida. Campinas: Autores Associados; 1995.

23. Carvalho JM. Cidadania no Brasil: o longo caminho. Rio de Janeiro: Civilização Brasileira; 2002.

24. Basaglia F. Escritos selecionados em saúde mental e re forma psiquiátrica. Rio de Janeiro: Garamond; 2005.

25. Saraceno B, Asioli F, Tognoni G. Manual de saúde mental: guia básico para atenção primária. São Paulo: Hucitec; 2001.

26. Saraceno B, Levav I, Kohn R. The public mental health significance of research on socio-economic factors in schizophrenia and major depression. World Psychiatry 2005; 4(3):181-185.

27. Thornicroft G, Tansella M. Growing recognition of the importance of service user involvement in mental health service planning and evaluation. Epidemiologia e Psichiatria Sociale 2005; 14(1):1-3.

28. M ato Grosso. Conselho Estadual de Saúde. Anais da V Conferência Estadual de Saúde de M ato Grosso. Cuiabá: Conselho Estadual de Saúde; 2003. [M imeo]

29. Jovchelovitch M. O processo de descentralização e municipalização no Brasil. Serviço Social \& Sociedade 1998; 56:34-49.

30. Carvalho Al. Conselhos de saúde no Brasil. Rio de Janeiro: FASE/IBAM ; 1995.

31. Lobosque AM. Clínica em movimento: por uma sociedade sem manicômios. Rio de Janeiro: Garamond; 2003.

Artigo apresentado em 24/04/2006

Aprovado em 29/02/2007 